\title{
Chromosomal Heteromorphisms and Karyotype Abnormalities in Humans
}

\author{
Neha Saran ${ }^{1}$, Baidyanath Kumar ${ }^{2 *}$ and Atul Kumar ${ }^{3}$ \\ ${ }^{1}$ School of Sciences, Suresh Gyan Vihar University, Mahal Jagatpura, Jaipur, Rajsthan, India \\ ${ }^{2}$ Department of Biotechnology, Patna Science College Patna University) Patna (Bihar), India \\ ${ }^{3}$ Department of Biotechnology, College of Commerce, \\ Arts and Science (Magadh University), Patna, India \\ *Corresponding author
}

\section{A B S T R A C T}

The presence of chromosome heteromorphisms in the karyotypes of two patient groups was compared. The first group of patients consisted of 138 infertile couples and the second group of patients were fetuses whose amniotic fluid samples were obtained during the same period $(\mathrm{n}=1130)$. In the infertile group, 18 individuals $(11$ males and seven females; $6.52 \%$ ) were found to have different kinds of chromosome heteromorphisms. In females,

\begin{tabular}{|l|}
\hline Ke y w or d s \\
Chromosomes, \\
Heteromorphisms, \\
Karyotype, \\
Infertility, \\
Banding pattern. \\
\hline Article Info \\
\hline Accepted: \\
26 April 2017 \\
Available Online: \\
10 May 2017 \\
\hline \hline
\end{tabular}
the frequency of heteromorphisms was $5 \%$ and in males $7.9 \%$. Eleven males who had heteromorphisms were oligozoospermic or azoospermic. The seven women with chromosome heteromorphisms had normospermic partners. Among 1,130 amniocentesis samples studied female karyotype in 543 and male karyotype in 587 fetuses were investigated. It was observed that the polymorphism was detected in nine $(1.65 \%)$ female and $11(1.87 \%)$ male fetuses. The parents of these fetuses were also karyotyped and all heteromorphisms were found to be inherited from either one of the parents. The association of chromosomal polymorphic variations with recurrent miscarriage was also studied.The results indicated that the recurrent miscarriage becomes a problem that affect an increasing number of couples with the frequency of about $1 \%$ in the couples who want to conceive. This study is based on comparison of chromosome Heteromorphism in the karyotypes of two groups. The first group was of 400 individuals with the history of more than two miscarriages and no live birth and as control group 200 individuals with one or more than one normal child. The study revealed that the frequency of chromosomal abnormalities and variations leading to recurrent miscarriage in couples was $18 \%$ Chromosomal rearrangements constituted $27.78 \%$ of the cases while heterochromatic variations constituted $72.22 \%$ of the chromosomal cause for recurrent miscarriages. In the present study, pericentric inversion of chromosome 9 and heteromorphism of chromosomes 1 were the most common findings. Present study indicates that there is need to evaluate the known heterochromatic variants as these variants play an important role in pregnancy loss.

\section{Introduction}

The term heteromorphism is especially applicable to normal variants observed by chromosome banding techniques. However, normal variations in morphology in certain regions of the human genome were noted even before the advent of chromosome banding. In the first Conference on Standardization in Human Cytogenetics in 
Denver in 1960/1966, chromosomes were divided into Groups A-G based on their relative sizes and positions of the centromeres. The $\mathrm{X}$ chromosome fell somewhere in the C-group. The $\mathrm{Y}$ was distinguishable from the G-group by its lack of satellites and somewhat distinctive morphology. At the London Conference in 1963, prominent secondary constrictions were identified near the centromeres in the no. 1 chromosome pair in the A- group, in a chromosome pair (no. 9) in the C-group and in a pair (no. 16) in the E-group. By the Chicago Conference in 1966, it was generally recognized that these regions and the $\mathrm{Y}$ varied in length, and that there were morphological variations in the short arms of the D- and Ggroup chromosomes. In the early 1970s, Q-, G- and C-banding techniques became widely used.

$\mathrm{Q}$ and G-banding introduced a new era in which individual chromosomes could be definitively identified. With this capability, it also became possible to localize regions variable in size and staining to specific chromosomes. In particular, Q- and Cbanding revealed distinct classes of heteromorphisms that were not necessarily detectable in non-banded chromosomes, but could be shown to be heritable in banded chromosomes. The most distinctive heteromorphism by Q-banding was the brightly fluorescent distal long arm of the $\mathrm{Y}$ chromosome. The size of this brightly fluorescent segment varied from being almost negligible in size to being the longest segment on the Y long arm. Q-banding also revealed variations in staining of chromosomes 3, 4, 13-15, and 21-22 (Caspersson et al., 1968; Caspersson et al., 1970; Geraedts and Pearson, 1974; Lin et al., 1976; Lubs et al., 1977).

Although G-banding techniques became widely used for chromosome identification,
C-banding revealed size variations of heterochromatin (h) around the centromeres of every chromosome that could be more easily quantitated than in non-banded chromosomes. The $\mathrm{h}$ regions of chromosomes $1,9,16$ and in the distal long arm of the Y, evident in non-banded chromosomes, were especially visible by C-banding.

Most polymorphic variants are familial and follow Mendalian inheritance from one generation to other with a low mutation rate (Bhasin (2005). De novo polymorphic chromosomal variants are rarer and appear, possibly as a result of an unequal crossover between heterochromatic regions of homologous chromosomes in meiosis. It is possible due to conjugation of repeated DNA sequences. De novo heterochromatic variants are considered to be large in size and to be associated with clinical conditions. However, Madon et al reported the increased frequency of variants in association with different clinical conditions such as reproductive failure, recurrent spontaneous abortions and even psychiatric disorders (Madon et al., 2005).

The chromosomal Heteromorphisms in humans have largely been reviewed by Borgaonkar, 1997; Sahin et al., 2008; Madon, 2005; Hong et al., 2011; Minocherhonji et al., 2009; Brothman et al., 2006; Chopade et al., 2012; Mau et al., 1997; Boronova et al., 2015; Akbas et al., 2010; Rao et al., 2006; Mierla and Veronica, 2012; Jeong et al., 2010; Mozdarani et al., 2007; Negvenkar et al., 2005; Dubey et al., 2005; Kosyakova et al., 2013; Ganguly and Kadam, 2014; Purandare et al., 2011; Yamini Sharad Pokale (2015) etc.

Because of the need for more data on the knowledge of the recurrence risks involved in case of Heteromorphisms and karyotype abnormalities, the present study was 
undertaken with the objective of investigating the role of heteromorphic variations and karyotype anomalies on infertility in male and female subjects.

\section{Materials and Methods}

\section{Patients}

In the present investigation the presence of chromosome Heteromorphisms in the karyotypes of two patient groups was compared. The first group of patients consisted of 138 infertile couples who consulted the Assisted Reproduction Techniques (ART) Center of our University between January 2014 and January 2016 because of male infertility (due to azoospermia or oligospermia), idiopathic infertility or recurrent failure of assisted reproduction techniques. The second group of patients were fetuses whose amniotic fluid samples were obtained during the same period $(n=1130)$. None of the pregnancies was obtained by ART and the reasons for referral were standard indications for amniocentesis such as abnormal serum screening levels or advanced maternal age. This group was considered to be a sample of the fertile population, as the fetus being karyotyped is the result of a spontaneous pregnancy. Fetal karyotyping was made due to the standard indications for prenatal diagnosis, such as abnormal maternal serum screening results.

\section{Cytogenetic analysis}

All studies were performed in our routine cytogenetics laboratory, surveyed annually by the national committee of quality control in cytogenetics laboratories. Peripheral blood samples were obtained from both male and female partners $(n=276)$ in the infertile group. Chromosomes were harvested from 72 h lymphocyte cultures and Giemsa-trypsin banding (G-banding) was performed.
Amniotic fluid samples were cultured in Amniomed complete medium (Biochrom AG, Germany) and G-banded chromosomes were analyzed after harvesting (Verma and Babu, 1995). When heteromorphisms were detected, the parental peripheral blood samples were also karyotyped. At least 20 metaphases were analyzed for each case and heteromorphisms were reported according to ISCN 2005 after selective banding studies, such as $\mathrm{C}$ and NOR banding were performed (ISCN, 2005; Verma and Babu, 1995).

Visualized heterochromatic polymorphisms of autosomes 1, 9, 16 and Y chromosome were included, as well as prominent stalks and satellites of D and G-group chromosomes. The findings were considered as heteromorphic if the chromosome region of interest was greater than the same region on its homolog (Wyandt and Tonk, 2004). As for the $\mathrm{Y}$ chromosome, if it was larger than the G-group chromosomes, it was reported as $\mathrm{Yqh}+$, and if smaller, as $\mathrm{Yqh}-$ (Wyandt and Tonk, 2004) The common pericentric inversion of chromosome 9; inv(9) (p11q13) was also considered as a heteromorphism.

When heteromorphisms were detected, all karyotypes were examined under light microscope.

The Chromosome Heteromorphisms in the karyotype of two groups of patients were also studied. The first group of patients with 400 individuals of 200 couples (age range 20 to 40 , mean 30 ), with the history of more than two miscarriages and no live birth and as control group 200 individuals of 100 couples with one or more than one normal child (age range 20 to 40 , mean 30), recruited simultaneously during the study at Preventive Life Care, AIIMS, New Delhi. Chromosome investigations were conducted by analysis of $\mathrm{G}$ banded chromosomes using $2 \mathrm{~mL}$ 
heparinized peripheral blood sample. Metaphase spreads were made from phytohemaglutinin stimulated peripheral lymphocytes using standard cytogenetic techniques. Cultures were harvested and Karyotyping was performed on G-bands produced with trypsin and Giemsa (GTG)banded chromosome preparations (Verma and Babu 1995). The metaphases were karyotyped using a Zeiss microscope (Carl Zeiss Light Microscopy, Germany) and MetaSystems software (Meta Systems, Germany). Heteromorphisms were reported according to International System for Chromosome Nomenclature ISCN 2009 (Shaffer et al., 2009). Visualized polymorphic variations in the length of the centromeric heterochromatin on the long arms of chromosomes 1,9 and 16 $(1 \mathrm{qh}+/-, \quad 9 \mathrm{qh}+/-$ and $16 \mathrm{qh}+/-)$ were documented. Distinct polymorphic variants of the size of satellites (ps+) and lengths of stalks (pstk+) of the acrocentric chromosomes (Akbas et al., 2010;, Rao et al., 2006;, Uehara et al., 1992; Kosyakova et al., 2013; Ganguly and Kadam, 2014) were also recorded. The pericentric inversion of chromosomes 9 was considered as a heteromorphism. For classification of variants, there should be at least twofold increase in the size of the corresponding region on the other homolog.

\section{Results and Discussion}

In the infertile group, 18 individuals (11 males and seven females; $6.52 \%$ ) were found to have different kinds of chromosome heteromorphisms (Table 1). In females, the frequency of heteromorphisms was $5 \%$ and in males $7.9 \%$. Eleven males who had heteromorphisms were oligozoospermic or azoospermic. The seven women with chromosome heteromorphisms had normospermic partners.

As for the 1,130 amniocentesis samples studied, we detected female karyotype in 543 and male karyotype in 587 fetuses. We observed polymorphisms in nine $(1.65 \%)$ female and $11(1.87 \%)$ male fetuses. The results of this second group are shown in table 2. The parents of these fetuses were also karyotyped and all heteromorphisms were found to be inherited from either one of the parents.

The most frequent types of heteromorphisms in the infertile group were inv(9) and D-group variants, each with a percentage of $1.45 \%$, followed by $9 \mathrm{qh}+/ 9 \mathrm{ph}+/ 9 \mathrm{qh}-, 16 \mathrm{qh}+$ and $\mathrm{Yqh}+/ \mathrm{Yqh}-$ variants $(1.09 \%$ each; Fig. 1). Inherited heteromorphisms were present in 20 fetuses $(1.77 \%)$, with inv (9) again being the most frequent $(0.71 \%)$, followed by D-group $(0.53 \%)$ and G-group variants $(0.18 \%)$. Other types of heteromorphisms were present in $0.36 \%$ of cases. The types of heteromorphisms and their percentages are shown in table 3.

The incidence of heterochromatic variation in sample has been presented in table 4 . Heterochromatic variations in couples with recurrent miscarriages have been presented in table 5 and figure 2.

Infertility affects $15 \%$ of all couples. The genetic reasons of infertility are complex and have different consequences. The causes can be chromosomal, involve single genes or be multifactorial and they can affect any stage of embryo development (Shah et al., 2003).

Chromosome analyses have been studied in large groups of infertile patients in recent years (Cortes- gutrienez et al., 2004; Nakamura et al., 2001; Yakin et al., 2005; Morel et al., 2004; Lissitsina et al., 2006; Madon et al., 2005). In some of these studies, chromosome heteromorphisms were reported to have a higher frequency than the normal population and were regarded as abnormalities (Nakamura et al., 2001; Yakin et al., 2005; Madon et al., 2005). 
Heteromorphisms of chromosomes have been observed from the early studies of cytogenetics and are believed to have no impact on (Brothman et al., 2006). They include varying sizes of heterochromatin blocks, satellite or repeat sequence regions and inversions. In the present study, our aim was to compare chromosome heteromorphisms detected during routine cytogenetic analyses of infertile couples with the ones detected in amniotic fluid samples of spontaneous pregnancies. In the present investigation this second group has been considered as a sample of normal population, as the polymorphisms were all shown to be inherited from one of the parents who had no fertility problems. The indications for fetal karyotyping were abnormal serum screening levels and increased maternal age. There were no findings detected during fetal ultrasound examination. Also, the parents of the fetuses without any phenotypic reflections were karyotyped when polymorphisms were detected. Previously, Yilmaz et al., 2007 reported a relationship between increased risks for trisomy 18 and fetal triploidy in prenatal maternal serum screening. In the present study, it is not easy to find an impact of heteromorphisms and abnormal maternal serum screening results as there were no phenotypic effects on the fetuses detected by ultrasonography. The parental phenotypes were also normal, at least for the evaluated parameter of infertility.

The frequency of heteromorphisms in infertile cases was detected and found to be significantly higher than the fetuses $(\mathrm{p}<0.001)$. In females, chromosome heteromorphism frequency was $5 \%$ and in males $7.9 \%$. This finding was consistent with the previous reports regarding chromosome heteromorphisms as abnormalities in infertile cases (Nakamura et al., 2001; Madon et al., 2005).
The cytogenetic analyses to both partners of infertile couples during routine genetic evaluation have been performed. Heteromorphisms were more frequently detected in males. However, women had also an increased ratio compared to the fetal karyotypes. All men with heteromorphisms had oligo or azoospermia. This could lead us to the hypothesis that heteromorphisms could interfere with male meiosis. Seven women with heteromorphisms had normospermic partners, and these couples had idiopathic infertility. The relationship of idiopathic infertility and female chromosome heteromorphisms needs further investigation and evaluation in larger groups of patients, with more detailed methods.

Regarding the types of heteromorphisms observed Lissitsina et al., (2006), in their study of 90 infertile men observed inv (9)(p11q13) three times more often than controls. On the other hand, they found a similar frequency of 9qh+ and Yqh+ in both groups (Lissitsina et al., 2006). In the present investigation, the overall frequency of heteromorphisms were higher in infertile cases, however, the most frequent types, inv (9) and D-group variants were similar in both groups $(p=0.2667$ and $p=0.1137$ respectively).

Brothman et al., (2006) reported the survey results of the Cytogenetics Committee of the College of American Pathologists and The American College of Medical Genetics and conclude that common cytogenetic variants are considered to be heteromorphic and of no clinical significance. The majority of clinical cytogeneticists would not even mention these variants in their reports except for pericentric inversions and rare variants. They also deduce that there are currently no standards in cytogenetics for reporting heteromorphisms (Brothman et al., 2006). 
Table.1 The polymorphisms determined in infertile cases

\begin{tabular}{|l|l|l|l|l|l|l|l|}
\hline $\begin{array}{l}\text { Chromosome } \\
\text { analysis indication } \\
\text { (n= 276) }\end{array}$ & 1 qh+ & 9qh+/- & Inv (9) & $16 q \mathrm{~h}+/-$ & Yqh+/- & $\begin{array}{l}\text { Group D } \\
\text { cenh+/s+ }\end{array}$ & Total \\
\hline $\begin{array}{l}\text { Azoospermia } \\
\text { (n=13) }\end{array}$ & 1 & & & & & & 1 \\
\hline $\begin{array}{l}\text { Oligospermia (n= } \\
\text { 1) }\end{array}$ & & & & & & & \\
\hline ART failure (n= 24) & & & & & 1 & & 1 \\
\hline $\begin{array}{l}\text { Pregnancy loss } \\
\text { after IVF (n= 2) }\end{array}$ & & & & & & & \\
\hline $\begin{array}{l}\text { Infertility } \\
\text { (unclassified) } \\
\text { (n=230) }\end{array}$ & & 3 & 4 & 3 & 2 & 4 & 16 \\
\hline $\begin{array}{l}\text { Secondary } \\
\text { infertility (n=6) }\end{array}$ & & & & & & & \\
\hline
\end{tabular}

Table.2 The polymorphisms determined in amniocentesis cases

\begin{tabular}{|l|l|l|l|l|l|l|l|l|}
\hline $\begin{array}{l}\text { Amniocentesis } \\
\text { indication (n= 1130) }\end{array}$ & 9qh+/- & $\begin{array}{l}\text { Inv } \\
(9)\end{array}$ & 16qh+/- & Yqh+/- & $\begin{array}{l}\text { Group D } \\
\text { Cenh+/s+ }\end{array}$ & $\begin{array}{l}\text { Group G } \\
\text { Cenh+/s+ }\end{array}$ & Multiple & Total \\
\hline $\begin{array}{l}\text { Maternal anxiety } \\
\text { (n=42) }\end{array}$ & & & & & & & & \\
\hline $\begin{array}{l}\text { Family history for } \\
\text { chromosome } \\
\text { abnormalities }\end{array}$ & 1 & & & & & & 1 & 2 \\
\hline $\begin{array}{l}\text { Abnormal fetal USG } \\
\text { (n= 63) }\end{array}$ & & & & & & & & \\
\hline $\begin{array}{l}\text { Advanced maternal } \\
\text { age (n= 383) }\end{array}$ & & 4 & & 1 & 3 & & & 8 \\
\hline $\begin{array}{l}\text { First trimester } \\
\text { screening trisomy 18 } \\
\text { risk (n=6 }\end{array}$ & & & & & & & & \\
\hline $\begin{array}{l}\text { First trimester } \\
\text { screening trisomy 21 } \\
\text { risk (n= 106) }\end{array}$ & & 3 & & & & & & 3 \\
\hline $\begin{array}{l}\text { Triple test trisomy } \\
\text { 21 risk (n= 463) }\end{array}$ & & 1 & 1 & & 3 & 2 & & 7 \\
\hline $\begin{array}{l}\text { Triple test trisomy } \\
\text { 18 risk (n= 25) }\end{array}$ & & & & & & & & 20 \\
\hline
\end{tabular}


Table.4 Frequency of heterochromatic variations in couples with recurrent miscarriages

\begin{tabular}{|c|c|c|c|c|}
\hline $\begin{array}{l}\text { Types of } \\
\text { heterochromatic } \\
\text { variations }\end{array}$ & $\begin{array}{l}\text { Chromosomes } \\
\text { with } \\
\text { heterochromatic } \\
\text { variations }\end{array}$ & $\begin{array}{l}\text { No. of } \\
\text { cases }\end{array}$ & $\begin{array}{l}\text { Frequency in } \\
\text { recurrent } \\
\text { miscarriage } \\
\text { group }\end{array}$ & $(\%)$ \\
\hline \multirow{4}{*}{$\begin{array}{l}\text { Variationj of ' } q \text { ' } \\
\text { heterochromatin }\end{array}$} & $1 \mathrm{qh}+$ & 6 & 23.07 & \multirow[t]{4}{*}{$38.46 \%$} \\
\hline & $9 \mathrm{qh}+$ & 2 & 7.69 & \\
\hline & $9 q h+$ & 1 & $\mathbf{3 . 8 5}$ & \\
\hline & $16 q h+$ & 1 & 3.85 & \\
\hline \multirow{4}{*}{$\begin{array}{l}\text { Presence of } \\
\text { satellite on short } \\
\text { arm "p" }\end{array}$} & 13ps+ & 1 & 3.85 & \multirow[t]{4}{*}{34.62} \\
\hline & $15 p s+$ & 2 & 7.69 & \\
\hline & 15pstk+ & 3 & 11.54 & \\
\hline & 21ps+ & 3 & 11.54 & \\
\hline \multirow[t]{3}{*}{ Inversion } & Inv (6) & 1 & $\mathbf{3 . 8 5}$ & \multirow[t]{3}{*}{26.92} \\
\hline & Inv (9) & 5 & 19.22 & \\
\hline & $\operatorname{Inv}(\mathbf{Y})$ & 1 & 3.85 & \\
\hline
\end{tabular}

Table.3 Number and percentages of chromosomal heteromorphisms detected in two groups

\begin{tabular}{|c|c|c|c|c|c|c|c|c|c|}
\hline \multirow{2}{*}{$\begin{array}{l}\text { Number of } \\
\text { individuals } \\
\text { with hetero } \\
\text { morphism }\end{array}$} & \multicolumn{9}{|c|}{ Number and percentage of variants } \\
\hline & \multicolumn{2}{|c|}{$9 q h+/ 9 q h-$} & \multirow{2}{*}{\begin{tabular}{|l|} 
Inv (9) \\
4 \\
$(1.45 \%)$
\end{tabular}} & \multicolumn{2}{|c|}{ Vqh+/vqh- } & \multirow{2}{*}{\begin{tabular}{|l|} 
D \\
Group \\
0 \\
\end{tabular}} & \multirow{2}{*}{\begin{tabular}{|l|} 
G \\
Group \\
$\mathbf{3}$ \\
$(\mathbf{1 . 0 9 \%})$
\end{tabular}} & \multirow{2}{*}{$\begin{array}{l}16 q h \\
+ \\
1 \\
(0.36 \\
\%)\end{array}$} & \multirow{2}{*}{\begin{tabular}{|l}
$1 \mathrm{qh}+$ \\
0
\end{tabular}} \\
\hline $\begin{array}{l}\text { Infertile group } \\
(n=276)\end{array}$ & $\begin{array}{l}18 \\
(6.52 \\
\%)\end{array}$ & $3(1.9 \%)$ & & $\begin{array}{l}3 \\
(1.09 \%)\end{array}$ & \begin{tabular}{|l|}
4 \\
$(1.5 \%)$
\end{tabular} & & & & \\
\hline $\begin{array}{l}\text { Amniocentesis } \\
\text { group }(n= \\
\text { 1130) }\end{array}$ & $\begin{array}{l}20 \\
(1.77 \\
\%)\end{array}$ & $\begin{array}{l}1 \\
(0.09 \%)\end{array}$ & $\begin{array}{l}8 \\
(0.71 \%)\end{array}$ & $\begin{array}{l}1 \\
(0.09 \%)\end{array}$ & \begin{tabular}{|l|}
6 \\
$(0.53 \%)$
\end{tabular} & \begin{tabular}{|l|}
2 \\
$(0.18 \%)$
\end{tabular} & $\begin{array}{l}1 \\
(0.09 \%)\end{array}$ & $\mathbf{0}$ & $\begin{array}{l}1 \\
(0.09 \%)\end{array}$ \\
\hline
\end{tabular}


Fig.1 Showing partial karyotypes of the infertile patients exhibiting samples of chromosomal Heteromorphisms. Idiograms are snown in the middle; $\mathrm{G}$ banded chromosomes are on the left; $\mathrm{C}$ banded chromosomes are on the right

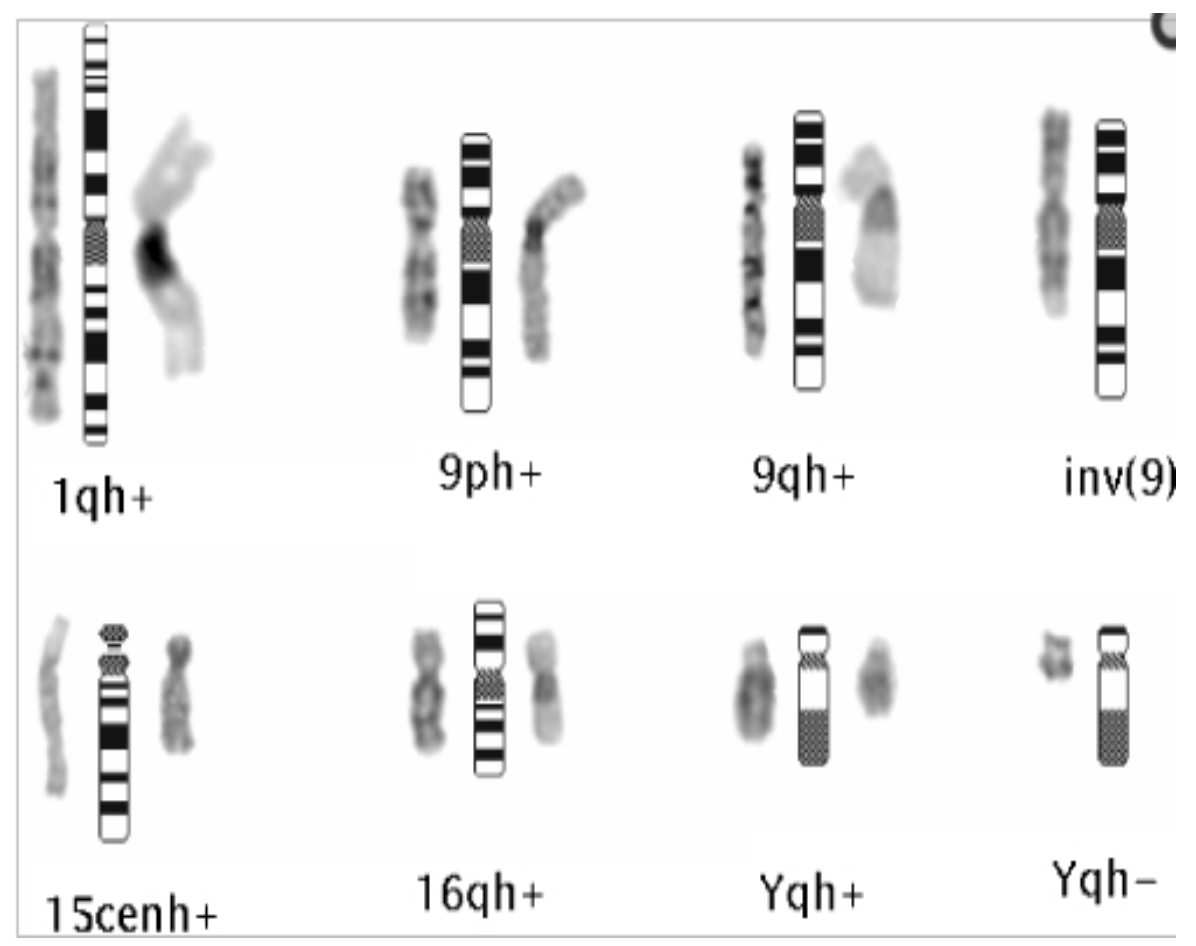

Fig.2 Occurrence of heterochromatic variations in Recurrent Miscarriage Group as compared to the Control

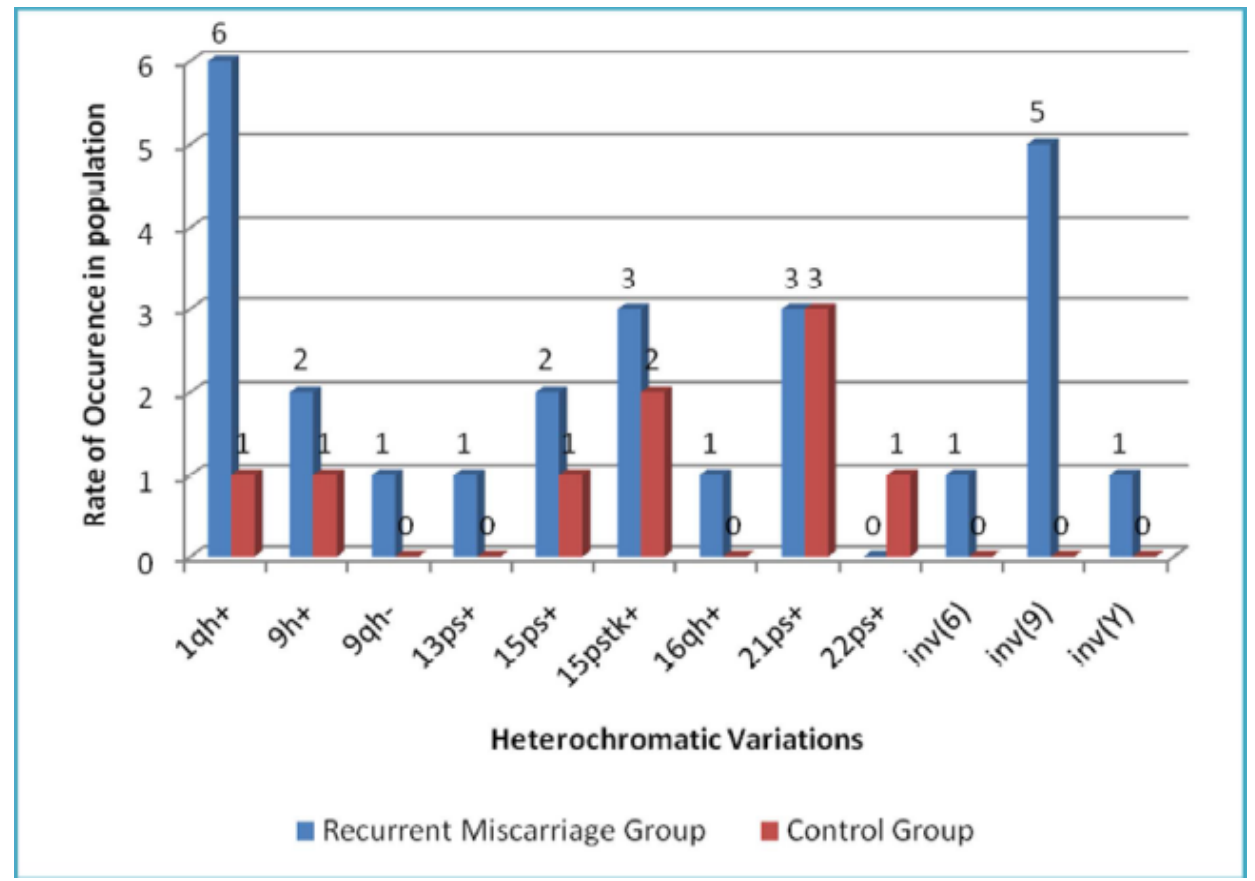


Table.3 Heterochromatic variations in couples with recurrent miscarriages

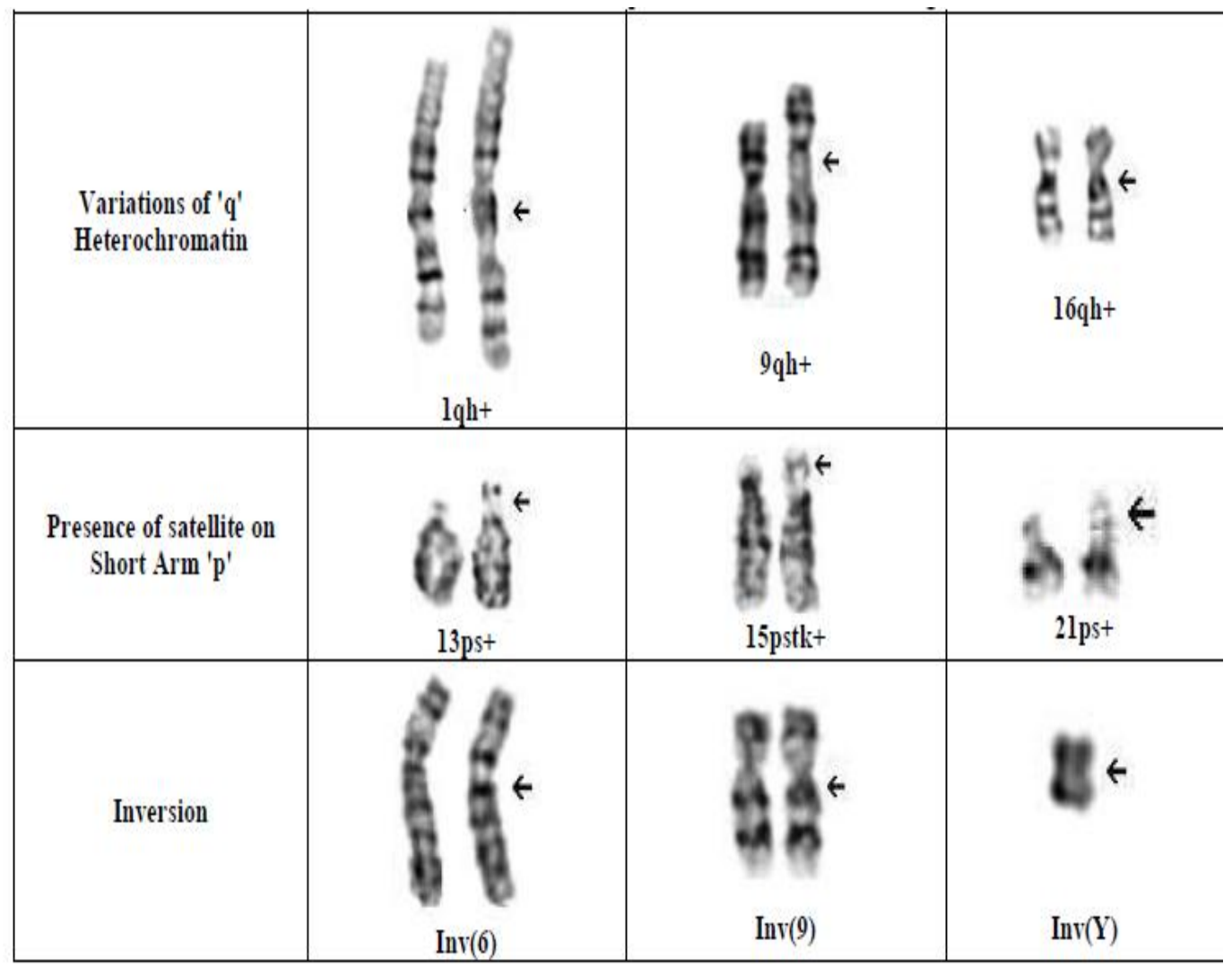

Polymorphic heterochromatic regions were found to alter the synapsis of homologous chromosomes during meiosis. These regions are the last to enter synapse, changing the timing of the whole division and leading first to probable meiotic defects, eventually to infertility (Codina et al., 2006). As for our cases, although we detected an increased ratio of heteromorphisms, it is not easy to regard the heteromorphisms as the sole reason for infertility and we believe this is rather coexistence than a correlation. We believe analyses at the molecular level will reveal mechanisms in more detail as following molecular genetic studies done in chromosome variants, the heterochromatin has been regarded to have more crucial cellular roles than previously thought. Thus, chromosome variants should not be ignored by cytogeneticists and clinicians, for contributory reasons that may not have been realized yet (Lissitsina et al., 2006; Madon et al., 2005; Starke et al., 2002).

The role of polymorphic chromosomal variations in infertility has been studied previously by many authors and despite of being over represented in infertile couples, no consistent data was found to correlate these variations with infertility. This subject continues to be an intriguing question. The results of Madon et al., (2005) evaluated 842 individuals attending an IVF clinic with primary infertility or repeated miscarriages, showed polymorphic variants in $28.82 \%$ of males and $17.19 \%$ of females5. Hong et al., (2011) studied the effect of polymorphic variants in the outcome of in vitro fertilization on 1978 couples and found 182 males presented with chromosomal variations $(9.2 \%)$. There was no any difference found among observed implantation rates but the 
incidence of first trimester pregnancy loss was higher compared to couples with normal karyotype (Hong et al., 2011). Minocherhomji et al., (2009) in the casecontrol study identified a highly statistically significant increase in the frequency of total chromosomal variants in infertile women $(28.31 \%$ vs. $15.16 \%)$ and infertile men $(58.68 \%$ vs. $32.55 \%)$ as epigenetic alterations associated with the infertility phenotype8. Brothman et al., (2006) concluded that common cytogenetic variants were considered to be heteromorphisms without clinical significance (Brothman et al., 2006).

Chopade et al., (2012) studied recurrent miscarriages, twenty nine individuals (16 males and 13 females; $9.06 \%$ ) were found to have chromosomal heteromorphisms in the acrocentric chromosomes and in males the frequency of heteromorphism was $10 \%$ and in the females 8.12\%10. Mau et al., (1997) reported chromosomal polymorphism in 13 out of 150 infertile male $(8.7 \%)$. The increase in the length of the secondary constriction in the long arm of chromosomes 1, 9 and 16 is also common in chromosome variations. The repeat segments may cause clinical symptoms because of increased highly repetitive DNA sequences.

The heterochromatin regions contain a significant amount of repetitious DNA, the repetitious DNA of these heterochromatin regions is heterogeneous. Chromosomal variants are an expression of morphological variability chromosome-related changes in the amount of heterochromatin. It is believed that the presence of chromosomal variant increases the risk of the nondisjunction of chromosome segregation. Heterochromatin has a specific role and behavior in the synapsis of human homologous chromosome (Boronova et al., 2015). Changes in structural element of the centromere due to polymorphic, heterochromatin may lead to the defective chromosome segregation.

\section{Variants of chromosome 1}

The polymorphism of 1qh+ has been reported in the relation with recurrent miscarriage or malignant disease by some authors. In inversion, inverted segment may cause synapsis failure, including asynapsis or early desynapsis, and pairing abnormalities of homologues leading to male infertility1. In general, inversions of heterochromatic regions are considered not to cause phenotypic abnormalities. In present study 6 cases with $1 \mathrm{qh}+$ were found.

\section{Variants of chromosome 9 and infertility}

The mechanisms of origin of inversions 9 are highly complex. The inv (9) is said to be common in the general population and it is inherited in a Mendalian fashion (Akbas et al., 2010; Rao et al., 2006). A small pericentric inversion of chromosome 9 is a most common inversion seen in human chromosomes with the incidence of $1-3 \%$ in the general population (Rao et al., 2006; Codina et al., 2006; Starke et al., 2002). Pericentric inversion 9, especially complete inv (9) (p11q13) has been reported in association with recurrent miscarriages, infertility and congenital anomalies (Sahin et al., 2008; Madon et al., 2005; Akbas et al., 2010; Jeong et al., 2010 Mozdarani et al., 2007; Negvenkar et al., 2005; Dubey et al., 2005; Kosyakova et al., 2013; Ganguly and Kadam, 2014). Inversion 9 has been considered to play significant role in chromosomal non-disjunction, and have variable effects on spermatogenesis, from azoopspermia to severely altered sperm morphology, motility and meiotic segregation.

During meiosis I, a loop will be formed in chromosomes with inversion and that can lead to production of abnormal and unbalanced gametes. Carriers of such inversion are at risk of having an offspring with unbalanced 
karyotype. It is suggested that inv (9) might have also some inter-chromosomal effect leading to a higher incidence of mitotic disturbances and it is known to be associated with aneuploidy such as mosaic Trisomy 21 (Madon et al., 2005).

In the present investigation it was observed that chromosome 9 showed the maximum variations which included $\mathrm{qh}+(11.54 \%)$ and inv (9) (19.23\%). The heterochromatic variations of chromosome 9 were significantly more frequent as compared to the control individuals.

\section{Polymorphic variations in acrocentric chromosomes}

D/Ggenome chromosomes are the common heteromorphisms showing increased heterochromatin at the chromosome telomere, the short arm, and the nucleolar organizing region (NOR). Heterochromatin located in centromeres has an essential role in spindle attachment and chromosome movement, meiotic pairing and sister chromatid cohesion. Chromatin variation in these regions causes defects in centromere function and kinetochore assembly, difficulty in homologous chromosome pairing, and impacts on cell division, thus affects gamete formation (Hong et al., 2011). No specific functions have been reported to be associated with the satellite segments (ps+). However, such variations in the couple may make the fetus susceptible to translocations which may lead to fetal wastage (Purandare et al., 2011).

In conclusion, the high incidence of heterochromatic variants of chromosome 1 and 9 ( $\mathrm{qh}+$ and inversion) is detected in the recurrent miscarriage cases. Therefore the study suggests the significantly higher incidence of pregnancy losses in those who are carriers of heterochromatic variations of chromosome 1 and 9. For the carriers there is a risk of transfer of abnormal chromosome which could result in chromosomally unbalanced gamete and formed a malformed offspring or spontaneous fetal death. As the variants play an important role in reproductive failure, it is suggested that the cytogeneticists should not ignore these variants. Carriers of an abnormal karyotype should be counseled thoroughly to avoid unnecessary reproductive wastage. Preconceptional prenatal genetic testing is also indicated. Molecular cytogenetics may increase the number of variants, leading to the detection of new forms of polymorphisms in the human genome which are not detectable by previous methods.

\section{Acknowledgement}

The authors are thankful to Dr. Baidyanath Kumar, Visiting Professor, Department of Biotechnology, Patna Science College, Patna for their involvement and support and suggestion for the study.

\section{References}

Akbas E, Senli H, Hallioglu O, Batmaz S and Erdogan N (2010): Association of Pericentric Inversion of Chromosome 9 (inv[9][p11q13]) and Genetic Diseases: Case Report, Labmedicine, 41(2), 96-98

Babu A, Agarwal AK, Verma S. (1998): A new approach in recognition of heterochromatic regions of human chromosomes by means of restriction endonucleases. Am J Hum Genet; 42:60-5.

Babu A, Verma RS. (1986): Characterization of human chromosomal constitutive heterochromatin. Can J Genet Cytol, Oct; 28(5):631-44.

Bhasin MK (2005): Human Population Cytogenetics: A Review, Int J Hum Genet, 5, 83-152 
Borgaonkar D.S (1997): Chromosomal variation in man: a catalogue of chromosomal variants and anomalies, (8th edn) Wiley-Liss, New York

Boronova I, Bernasovska J, Cakanova G, Ferenc P, Petrejcikova E and Szabadosova V (2015): Heterochromatin Variants in Slovak Women with Reproductive Failure., Int J Hum Genet, 15(1),1-5

Brothman AR, Schneider NR, Saikevych I, and Cooley LD, Butler MG, Patil S, et al., (2006): Cytogenetics Resource Committee, College of American Pathologists/American College of Medical Genetics. Cytogenetic heteromorphisms: Survey results and reporting practices of Giemsa-band regions that we have pondered for years. Arch Pathol Lab Med; 130:9479.

Brothman A, Schneider N, Saikevych I, and Cooley L, Butler M, Patil S (2006): Cytogenetics Resource Committee, College of American Pathologists/American College of Medical Genetics. Cytogenetic heteromorphisms: Survey results and reporting practices of Giemsa-band regions that we have pondered for years, Arch Pathol Lab Med., 130, 947949

Caspersson T, Farber S, Foley GE, Kudynowski J, Modest EJ, Simonsson E, Wagh U, Zech L (1968) Chemical differentiation along metaphase chromosomes. Exp Cell Res 49:219222

Caspersson T, Zech L, Johansson C (1970) Analysis of human metaphase chromosome set by aid of DNA-binding fluorescent agents. Exp Cell Res 62:490-492

Chicago Conference (1966) Standardization in human cytogenetics. Birth defects: original article series, Vol 2, no 2. The National Foundation, New York

Chopade S, Chopade DK, Harde H (2012): Impact of Chromosomal Heteromorphisms on Recurrent Miscarriages, Human Genet Embryol., 2(1),

Codina-Pascual M, Navarro J, Oliver-Bonet M, Kraus J, Speicher MR, Arango O, (2006): Behaviour of human heterochromatic regions during the synapsis of homologous chromosomes. Hum Reprod, 21(6):1490-7.

Cortés-Gutiérrez EI, Cerda-Flores RM, Dávila-Rodríguez MI, HernándezHerrera R, Vargas-Villarreal J, LealGarza CH.(2004): Chromosomal abnormalities and polymorphisms in Mexican infertile men. Arch Androl; 50:261-5

Denver Conference (1960/1966) A proposed standard system of nomenclature of human mitotic chromosomes. Lancet 1:1063-1065; reprinted in Chicago Conference, pp 12-15

Dubey S, Chowdhury M, Prahlad B, Kumar V, Mathur R, Hamilton S, Kabra M, Menon P and Verma I (2005): Cytogenetic causes for recurrent spontaneous abortions - an experience of 742 couples (1484 cases), Indian J Hum Genet., 11(2), 94-98

Ergul E. (2013): Heteromorphic variants of chromosome 9, Molecular Cytogenetics, 6, 14

Ganguly B and Kadam N (2014): Prenatal Diagnosis of Fetus with Short Limbs Caused by Three Abnormal Chromosomes Inherited from Parents, Int J Hum Genet, 14(2), 83-90

Geraedts JPM, Pearson PL (1974): Fluorescent chromosome polymorphisms; frequencies and segregation in a Dutch population. Clin Genet 6:247-257 
Hong Y, Zhou Y, Tao J, Wang S and Zhao X (2011): Do polymorphic variants of chromosomes affect the outcome of in vitro fertilization and embryo transfer treatment? Hum Reprod, 26(4), 933940

ISCN (2005): An international system for human cytogenetic nomenclature. Shaffer LG, Tommerup N, editors. Basel: Karger, 2005.

Jeong S, Kim B, Yu J (2010): De Novo Pericentric Inversion of Chromosome 9 in Congenital Anomaly. Yonsei Med J 51(5), 775-780

Kosyakova N, Grigorian A, Liehr T, Manvelyan M, Simonyan I, Mkrtchyan $\mathrm{H}$, Aroutiounian R, Polityko A, Kulpanovich A, Egorova T, Jaroshevich E, Frolova A, Shorokh N, Naumchik I, Volleth M, Schreyer I, Nelle H, Stumm M, Wegner R, Reising-Ackermann G, Merkas M, Brecevic L, Martin T, Rodríguez L, Bhatt S, Ziegler M, Kreskowski K, Weise A, Sazci A, Vorsanova S, Cioffi $\mathrm{M}$ and and Ergul E (2013): Heteromorphic variants of chromosome 9, Molecular Cytogenetics, 6,14

Lissitsina J, Mikelsaar R, Punab M. (2006): Cytogenetic analyses in infertile men. Arch Androl; 52(2):91-5.

Lin CC, Gideon MM, Griffith P, Smink WK, Newton DR, Wilkie L, Sewell LM (1976) Chromosome analysis on 930 consecutive newborn children using quinacrine fluorescent banding technique. Hum Genet 31:315-328

London Conference (1963) Normal human karyotype. Cytogenetics 2:264-268; reprinted in Chicago Conference 1966, pp 18-19

Lubs HA, Patil SR, Kimberling WJ, Brown J, Cohen M, Gerald P, Hecht F, Myrianthopoulos N, Summit RL (1977): Q and C-banding polymorphisms in 7 and 8 year old children: racial differences and clinical significance. In: Hook E, Porter IH (eds) Population cytogenetic studies in humans. Academic Press, New York, pp 133-159

Madon PF, Athalye AS, Parikh FR. (2005): Polymorphic variants on chromosomes probably play a significant role in infertility. Reprod Biomed Online; 11(6):726-32.

Mau UA, Backert IT, Kaiser P and Kiesel L (1997): Chromosomal findings in 150 couple referred for genetic counseling prior to intracytoplasmic sperm injection, Hum Reprod, 12(5), 930-937

Minocherhomji S, Athalye A, Madon P, Kulkarni D, Uttamchandani S, Parikh F (2009): A case-control study identifying chromosomal polymorphic variations as forms of epigenetic alterations associated with the infertility phenotype, Fertility and Sterility, 92(1), 88-95

Mierla D, Veronica S (2012): Association of Pericentric Inversion of Chromosome 9 and Infertility in Romanian Population, a Journal of Clinical Medicine, 7(1), 2529

Mozdarani H, Meybodi A and Karimi $\mathrm{H}$ (2007): Pericentric inversion of chromosome 9[inv (9) (p11q12)] on infertility, Indian J Hum Genet., 13(1) 26-29

Morel F, Douet Guilbert N, Le Bris MJ, Amice V, Le Martelot MT, Roche S, (2004): Chromosomal abnormalities in couples undergoing intracytoplasmic sperm injection. A study of 370 couples and review of the literature. Int $\mathbf{J}$ Androl; 27(3):178-82.

Nakamura Y, Kitamura M, Nishimura K, Koga M, Kondoh N, Takeyama M, et al., (2001): Chromosomal variants among 1790 infertile men. Int J Urol 2001; 8:49-52. 
Nagvenkar P, Desai K, Hinduja I and Zaveri K (2005): Chromosomal studies in infertile men with oligozoospermia and non-obstructive azoospermia, Indian J Med Res., 122, 34-42

Purandare H, Fernandez NV, Deshmukh SV and Chavan S (2011): Heterochromatic variations and Pregnancy losses in Humans, Int J Hum Genet., 11, 167-175

Rao B, Kerketta L, Korgaonkar S, Ghosh K (2006): Pericentric inversion of chromosome 9 [inv (9) (p12q13)]: its association with genetic diseases. Ind $\mathbf{J}$ Hum Genet, 12(3), 129-132

Sahin F., Yilmaz Z., Yuregir O.O., Bulakbasi T. and Ozer O (2008): Chromosome heteromorphisms: an impact on infertility, J Assist Reprod Genet., 25, 191-195

Shah K, Sivapalan G, Gibbons N, Tempet H, Griffin DK. (2003): The genetic basis of infertility. Reproduction; 126:13-25.

Shaffer L.G., Slovak M.L., Campbel L.J., ISCN 2009: an International System for Human Cytogenetic Nomenclature. S Karger Publishing, Basel, Switzerland, 53-54

Starke H, Seidel J, Henn W, Reichardt S, Volleth M, Stumm M, (2002): Homologous sequences at human chromosome 9 bands p12 and q13-21.1 are involved in different patterns of pericentric rearrangements. Eur J Hum Genet; 10(12):790-800.

Uehara S, Akai Y, Takeyama Y, Takabayashti T, Okamura K, Yajima A (1992): Pericentric Inversion of Chromosome 9 in Prenatal Diagnosis and Infertility, Tohoku J. Exp. Med.,166(4), 417-427

Verma R and Babu A (1995): Human chromosomes: Principles and Techniques, Second edition, McGraw Hill, New York

Verma RS, Babu A. (1995): Human chromosomes: principles and techniques, Chapter 3., 2nd edn. New York: McGraw Hill; p. 78-86.

Wyandt HE, Tonk VS. (2004): Atlas of human chromosome heteromorphisms. Dordrecht: Kluwer; 2004. p. 33-44.

Yakin K, Balaban B, Urman B. (2005): Is there a possible correlation between chromosomal variants and spermatogenesis? Int J Urol; 12:984-9.

Yamini Sharad Pokale (2015): Does a Heterochromatic variant affect the Human Reproductive outcome? Research Journal of Recent Sciences, 4, 108- 113

Yilmaz Z, Sahin FI, Tarim E, Kuscu E. Triploides (2007): In first and second trimester pregnancies in Turkey. Balkan J Med Genet; 10(2):71-75.

\section{How to cite this article:}

Neha Saran, Baidyanath Kumar and Atul Kumar. 2017. Chromosomal Heteromorphisms and Karyotype Abnormalities in Humans. Int.J.Curr.Microbiol.App.Sci. 6(6): 2940-2953. doi: https://doi.org/10.20546/ijcmas.2017.605.333 